\title{
BIOMASSA SECA ESTIMADA EM ÁREAS DE PASTAGENS COM DADOS DE SENSORIAMENTO REMOTO: ESTUDO DE CASO NA BACIA HIDROGRÁFICA DO RIO VERMELHO - GOIÁS
}

\begin{abstract}
Gabriel Alves Veloso ${ }^{1}$
Janete Rego Silva ${ }^{2}$

Manuel Eduardo Ferreira ${ }^{3}$

Resumo

Laerte Guimarães Ferreira Júnior ${ }^{3}$

Objetivo deste trabalho foi estimar a biomassa seca em áreas de pastagens com dados satelitários, bem como, dados de campo em áreas de pastagem no Cerrado goiano. $\mathrm{O}$ experimento foi realizado em áreas de pastagens na Bacia Hidrográfica do Rio Vermelho, porção oeste de Goiás, com a utilização das imagens do satélite Landsat 8. A estimativa deste parâmetro foi obtida combinando os algoritmos SEBAL (Surface Energy Balance Algorithm for Land) e o modelo CASA (Carnegie Ames Stanford Approach). Dentre os resultados, a análise da biomassa seca apresentou um melhor ajuste com o método SEBAL/CASA. Portanto, a estimativa da biomassa seca da pastagem com dados climáticos locais, bem com a calibração dos modelos com dados biofísicos específicos, demonstra ser um bom método para avaliar a qualidade de pastos em termos de produtividade e recuperação.
\end{abstract}

Palavras-chaves: Pastagem; Landsat 8; Cerrado; Modelagem.

\section{ESTIMATED DRY BIOMASS IN PASTURE AREAS WITH REMOTE SENSING DATA: CASE STUDY IN THE HYDROGRAPHIC BASIN OF RIO VERMELHO - GOIÁS}

\begin{abstract}
This paper aimed to estimate the dry biomass in pasture areas with satellite data from models with specific pasture information in the biome Cerrado. The experiment was carried out in pasture areas at the Rio Vermelho Hydrographic Basin, the western portion of Goiás state, using Landsat 8 satellite images. The estimation of this parameter was obtained by combining the SEBAL algorithms (Surface Energy Balance Algorithm for Land) and the CASA model (Carnegie Ames Stanford Approach). The analysis of dry biomass showed the best product with the SEBAL / CASA method. Therefore, estimating pasture dry biomass with local climatic data, as well as calibrating the models with specific biophysical inputs, proves to be a good method to assess pasture quality in terms of productivity and recovery.
\end{abstract}

Keywords: Pasture; Landsat 8; Cerrado; Modeling.

\footnotetext{
${ }^{1}$ Professor Universidade Federal do Pará - UFPA, Faculdade de Geografia, campus Altamira/Lab. de Geografia Física e Cartografia - LAGEO. Email: gabrielveloso.geo@gmail.com

${ }^{2}$ Professora Universidade Estadual de Goiás - UEG, Unidade Universitária de Niquelândia.

Email: janete.silva@ueg.br

${ }^{3}$ Professor Universidade Federal do Goiás - UFG, Lab. de Processamento digital de imagens e Geoprocessamento - LAPIG. Email: manuel@ufg.br; laerte@ufg.br
} 


\section{BIOMASA SECA ESTIMADA EN ZONAS DE PASTOS CON DATOS DE DETECCÍON REMOTA: ESTUDIO DE CASO EN LA CUENCA HIDROGRÁFICA DE RIO VERMELHO - GOIÁS}

\section{Resumen}

El objetivo de este trabajo fue estimar la biomasa seca en áreas de pasto con datos satelitales, así como datos de campo en áreas de pasto en el Cerrado de Goiás. El experimento se llevó a cabo en áreas de pastos en la Cuenca Hidrográfica del Río Vermelho, porción occidental de Goiás, utilizando imágenes satelitales Landsat 8. La estimación de este parámetro se obtuvo mediante la combinación de los algoritmos SEBAL (Surface Energy Balance Algorithm for Land) y el Modelo CASA (Enfoque Carnegie Ames Stanford). Entre los resultados, el análisis de biomasa seca mostró un mejor ajuste con el método SEBAL / CASA. Por lo tanto, estimar la biomasa seca de los pastos con datos climáticos locales, así como calibrar los modelos con datos biofísicos específicos, resulta ser un buen método para evaluar la calidad de los pastos en términos de productividad y recuperación.

Palabras-clave: Pastajen; Landsat 8; Cerrado; Modelado.

\section{INTRODUÇÃO}

A natureza extensiva das pastagens no Brasil, combinada com a necessidade de dados mais precisos e detalhados sobre a qualidade dos pastos, tem estimulado o desenvolvimento de novas técnicas de sensoriamento remoto, que auxiliem em políticas públicas do setor agropecuário. O uso destas, por sua vez, tem apresentado enorme potencial no mapeamento de pastagens cultivadas em diferentes escalas espaciais e temporais, no qual é possível inferir o vigor vegetativo do pasto e avaliar o potencial nutricional deste para o rebanho. Dessa forma, trabalhos como de Veloso et al. (2020) que estimou o potencial de expansão da pecuária no estado de Goiás com dados do sensor MODIS (Moderate-Resolution Imaging Spectroradiometer) e de Parente et al. (2019) que mapearam a dinâmica dos pastos no Brasil entre os anos de 1985 a 2017 com imagens da série histórica dos satélites Landsat 5 e Landsat 8, demonstram a potencialidade da aplicação das técnicas de Sensoriamento Remoto para a gestão e planejamento dessas áreas.

Ademais, essas técnicas vêm contribuindo na obtenção de variáveis biofísicas, sobretudo aquelas ligadas à produção de biomassa em ecossistemas naturais e áreas antrópicas, estes são dados importantes para o planejamento de qualquer região. A biomassa pode ser entendida como a quantidade de matéria viva presente em um determinado tempo e por área (GRISI, 2000). No entanto, tais informações ainda são cercadas de muitas incertezas, atribuídas 
Biomassa seca estimada em áreas de pastagens com dados de sensoriamento remoto: estudo de caso na bacia hidrográfica do rio Vermelho - Goiás

à insuficiência de dados concretos sobre a eficiência dos diversos sistemas (naturais ou não), especialmente ao converter o carbono atmosférico em biomassa, e com isso aumentar a produtividade primária. Dessa forma, torna-se relevante o desenvolvimento de modelos para a estimativa da biomassa acima do solo, capazes de indicar com maior precisão os estoques de carbono nestes ambientes (GUSSON, 2014).

Dentre estes modelos, podemos destacar os biogeoquímicos para quantificação do carbono em grandes áreas, conhecido por Forest-BGC, desenvolvido para análises em grandes escalas temporais e espaciais, combinado com dados de sistema de informações geográficas (RUNNING e COUGHLAN, 1988). Outro modelo é o MBL-GEM, desenvolvido para estudos de florestas tropicais em escala local ou regional (RASTETTER et al., 1991 e MCKANE et al., 1995). Ambos são utilizados em estudos da dinâmica do carbono e nitrogênio, nos compartimentos solo e vegetação.

Ainda, tem-se o modelo CASA (POTTER et al., 1993; POTTER et al., 1998), desenvolvido para a análise global da produtividade primária líquida (NPP), utiliza dados de sensoriamento remoto (paramétricos) para gerar produtos de NPP com resolução espacial de 1 grau de latitude em intervalos mensais (aproximadamente $100 \mathrm{~km}^{2}$ ).

Dessa forma, vêm sendo desenvolvidas metodologias que estimam a biomassa seca através dos parâmetros espectrais de imagens ópticas, e com poucos dados de superfície. Uma das metodologias que se destaca é o produto global MOD17A2H (500m) do sensor MODIS, que fornece medidas de produtividade primária bruta. Esse produto é utilizado para definir o fluxo dinâmico de carbono terrestre, bem como sua sazonalidade, sendo de significativa importância para a modelagem climática (PAIVA e FERNANDES, 2015). No entanto, essa metodologia apresenta algumas limitações, em que a mesma "agrupa" diferentes classes de uso e cobertura do solo, assim e considerando a dinâmica de uso e ocupação do bioma Cerrado, pode-se obter elevados erros deste produto.

As possíveis fontes de erro deste produto, diz respeito aos dados climáticos, o qual utiliza as informações do Global Modeling and Assimilation Office - GMAO (resolução espacial de $0,5^{\circ}$ a $0,625^{\circ}$ ), com resolução espacial significativamente maior. Bem como, os dados de cobertura e uso da terra (produto MCD12Q1), em que se houver erro na discriminação da classe de cobertura e uso, pode-se elevar o erro do produto MOD17A2H.

Portanto, a utilização de dados meteorológicos locais e um bom produto de classificação de uso do solo podem melhorar significativamente os dados estimados da biomassa seca. Além 
disso, a utilização de imagens com resolução média (30 metros), como as do Landsat 8 sensores OLI (óptico) e TIRS (termal), pode proporcionar a análise dessas variáveis biofísicas em níveis de propriedade rural, auxiliando na identificação de possíveis áreas de degradação, tornando possível uma tomada de decisão mais eficiente.

Com base no exposto, tem-se o objetivo de estimar a biomassa seca em áreas de pastagens, gerando um modelo, tendo como referência/área-teste a Bacia Hidrográfica do Rio Vermelho - BHRV, no estado de Goiás (área core do Cerrado), dada a importância desta região para a pecuária nacional, e como um dos principais afluentes do rio Araguaia-Tocantins. Atualmente, esta bacia possui $68 \%$ de sua superfície antropizada, voltada principalmente para a produção agropecuária (VIEIRA et al., 2015). Para tanto, são utilizadas imagens dos sensores OLI e TIRS do satélite Landsat 8, além de parâmetros biofísicos específicos do gênero Urochloa e dados climáticos locais.

\section{MATERIAIS E MÉTODOS}

\section{Caracterização das pastagens na Bacia Hidrográfica do Rio Vermelho}

Os dados biofísicos de campo para parametrização do modelo foram obtidos na Bacia Hidrográfica do Rio Vermelho (BHRV), a qual está localizada no oeste do estado de Goiás, entre os paralelos $14^{\circ} 55^{\prime}$ e $16^{\circ} 20^{\prime}$ Sul e os meridianos $50^{\circ} 00^{\prime}$ e $51^{\circ} 30^{\prime}$ ' Oeste. Compreende uma área de 10.824,60 km², abrangendo 11 municípios goianos, de forma parcial e/ou completa (Goiás, Aruanã, Matrinchã, Britânia, Jussara, Santa Fé de Goiás, Fazenda Nova, Novo Brasil, Buriti de Goiás, Faina e Itapirapuã) (VIEIRA, 2013; SANTOS, 2014).

A fim de avaliar e caracterizar as áreas de pastagens na BHRV foram selecionadas cinco propriedades rurais, com pastos do gênero Urochloa, com diferentes condições de uso e manejo, os quais estão localizados em diferentes unidades geoambientais da bacia (em termos de solos e relevo), sendo que quatro propriedades estão no município de Goiás (Faz. Dois Córregos, Faz. Estância Paraíso, Faz. N. Sr. ${ }^{a}$ das Graças e Faz. Jatobá) e uma no município de Britânia (Faz. Ajuricaba). Na Figura 01 estão indicados os pontos de coleta nas cinco propriedades elencadas.

Os critérios de seleção adotados compreendem a presença de propriedades em diferentes unidades geoambientais da BHRV (VIEIRA, 2013; SANTOS, 2014), tal como ocorre com a propriedade Dois Córregos, inserida na alta porção da bacia, com solos rasos e uma vegetação de Cerradão, ou na propriedade Nossa Senhora das Graças, na média porção da bacia, com Latossolo e terrenos mais planos (solos mais profundos). Outro fator considerado foi a logística 
Biomassa seca estimada em áreas de pastagens com dados de sensoriamento remoto: estudo de caso na bacia hidrográfica do rio Vermelho - Goiás

de acesso às propriedades, garantindo sempre que possível um acesso rápido por rodovias pavimentadas, ou próximas destas. Tais condições otimizaram a atividade de campo, em geral realizada em apenas dois dias para cada campanha.

Figura 01 - Localização da BHRV no estado de Goiás e das cinco propriedades rurais
visitadas, durante doze campanhas de campo (de outubro de 2014 a setembro de 2015).

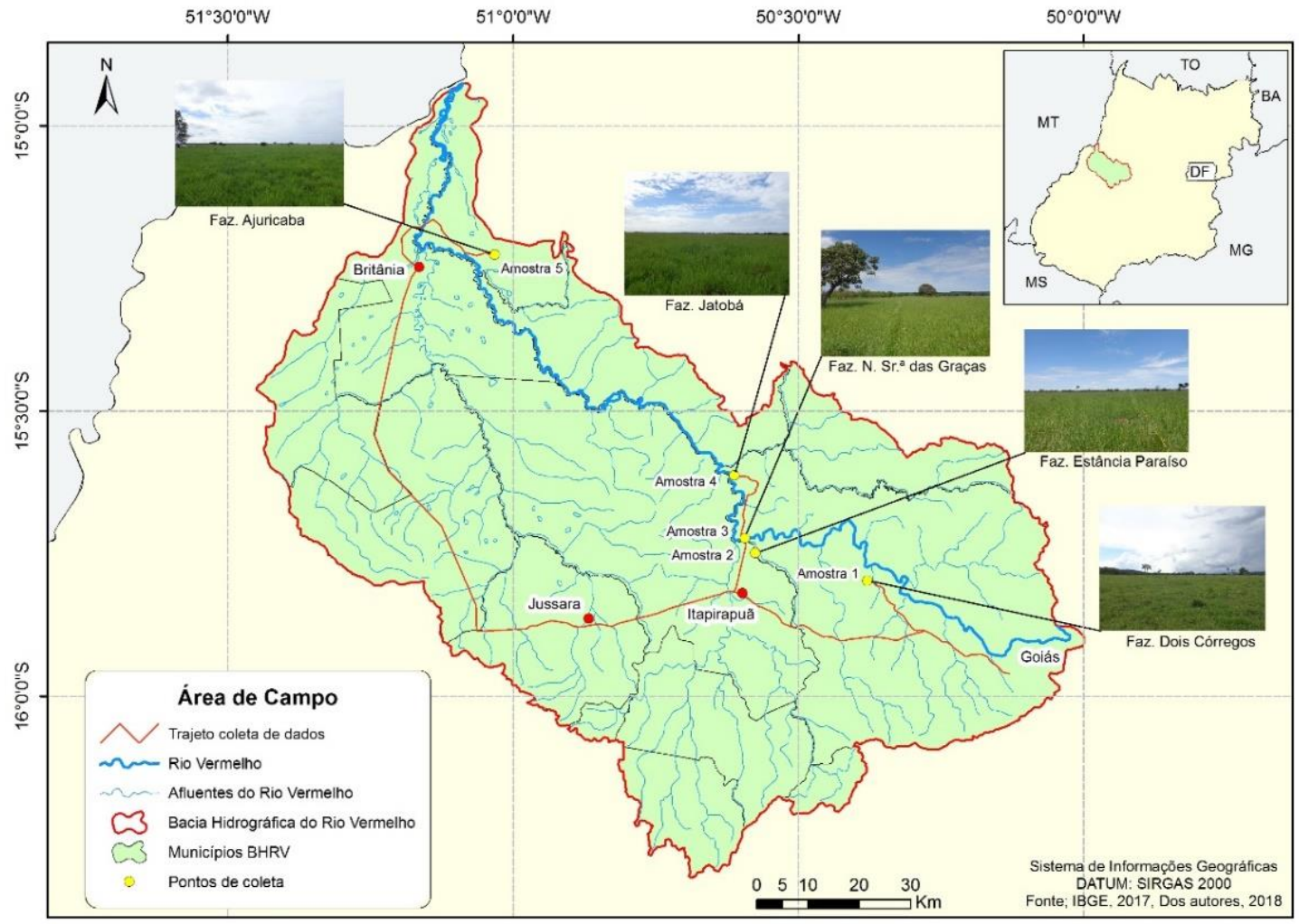

Fonte: Dos autores, 2015.

Os dados de campo foram coletados por uma equipe multidisciplinar do Laboratório de Processamento de Imagens e Geoprocessamento - LAPIG, utilizando-se uma trena de $50 \mathrm{~m}$ (determinando um transecto), trena de $3 \mathrm{~m}$ (medição da altura da pastagem), pin-point (amostragem dos alvos no solo); câmera fotográfica digital (padrão RGB), para a tomada das fotografias verticais da pastagem. A coleta da biomassa foi realizada removendo toda a biomassa até o solo, com uma tesoura de jardinagem e armazenada em sacos de nylon.

Em cada propriedade visitada em cada campanha (dentre as cinco selecionadas), foi determinada uma direção com uma bússola (azimute de $180^{\circ}$ ), implantando um transecto de 50 $\mathrm{m}$ rente à pastagem, com coleta de dados a cada 2 metros (26 coletas por transecto). Convencionou-se coletar os dados na seguinte ordem: a medição da altura da pastagem com uma trena, amostragem dos alvos (solo, rocha ou vegetação) com método pin-point, e a tomada de fotografias verticais, a uma altura média de 1,4 m. Posteriormente, foi feita a coleta da 
biomassa em três pontos do transecto (distâncias de 0 m, 26 m e 50 m), separada em biomassa verde e seca, e armazenada em sacos para a análise no laboratório, todas as etapas estão ilustradas na Figura 02.

\section{Figura 02 - Etapas do procedimento de coleta dos dados em campo, com os referidos}

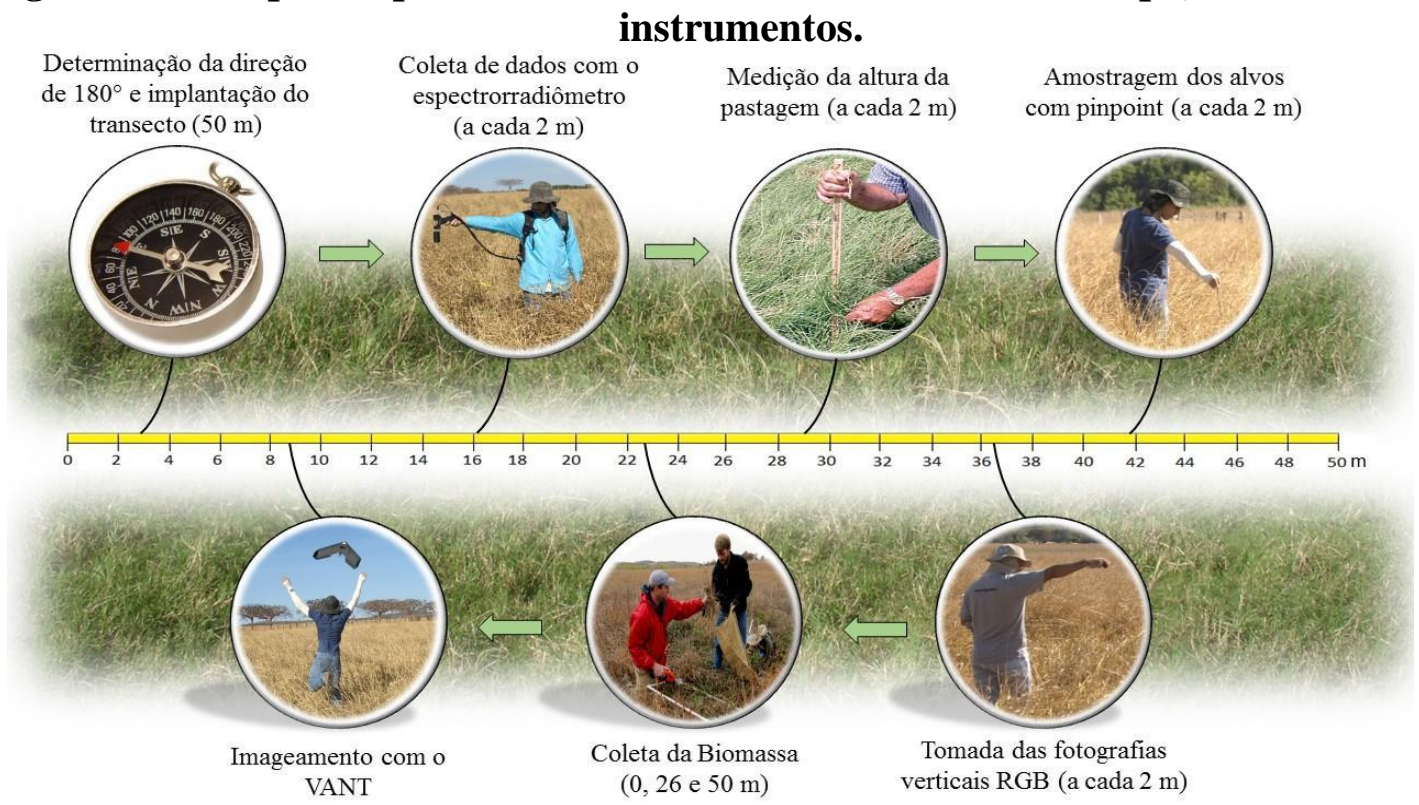

Fonte: Dos autores, 2015.

Em laboratório, procedeu-se com a pesagem prévia, secagem e nova pesagem das biomassas verde e seca. Inicialmente, a biomassa coletada em campo foi pesada e colocada para secar em estufa em temperatura de $70{ }^{\circ} \mathrm{C}$, por aproximadamente 72 horas; após essa etapa, a matéria seca foi pesada novamente para que fosse possível avaliar a perda de água. As informações foram organizadas em tabelas e os valores foram convertidos $\mathrm{de} \mathrm{g} / \mathrm{m}^{2}$. Estas etapas compreendidas na secagem e pesagem da biomassa (verde e seca) estão ilustradas na Figura 03.

Figura 03 - Etapas do procedimento de secagem e pesagem das amostras de biomassa verde e seca.

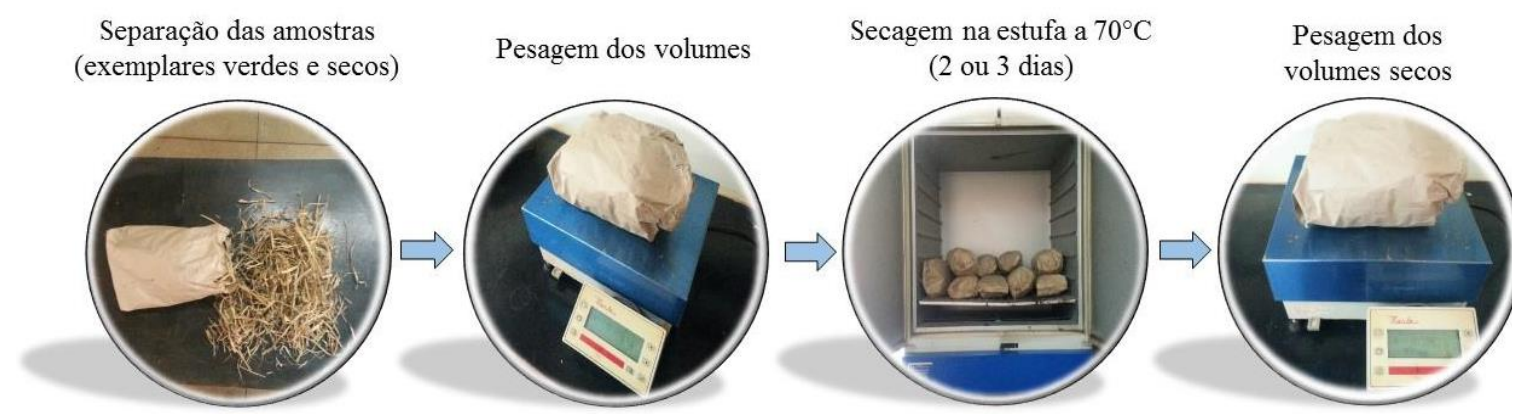

Fonte: Dos autores, 2015 
Biomassa seca estimada em áreas de pastagens com dados de sensoriamento remoto: estudo de caso na bacia hidrográfica do rio Vermelho - Goiás

\section{Processamento Digital das Imagens Landsat 8 (modelo SEBAL/CASA)}

A fim de realizar-se uma extrapolação dos dados de campo foram obtidas avaliações da estimativa da biomassa seca acima do solo, por meio de sensoriamento remoto, a qual pode ser feita ao combinar o modelo de estimativa da radiação fotossinteticamente ativa absorvida pela vegetação - APAR (MONTEITH, 1972), juntamente com o modelo de eficiência do uso da luz na fotossíntese (FIELD et al., 1995). Bastiaanssen e Ali (2003) consideram que o fator água do modelo de Field et al. (1995) pode ser representado pela fração evaporativa, que integra o conjunto de procedimentos do algoritmo Surface Energy Balance Algorithm for Land - SEBAL, com objetivo de estimar a evapotranspiração através da quantificação dos componentes do balanço de energia.

Para este procedimento metodológico foram utilizadas as seguintes bases cartográficas, com o objetivo de calcular a biomassa seca para a área de estudo, a) Imagens MOD17A2H, MOD13Q1H e MOD15A2H do sensor MODIS, disponibilizadas pelo Serviço Geológico Norte-Americano (USGS) e pelo portal do Laboratório de Processamento de Imagens e Geoprocessamento - LAPIG/UFG; b) Imagens do satélite Landsat 8, sensores OLI e TIRS, para a BHRV, disponibilizadas pelo Serviço Geológico Norte-Americano (USGS); c) Séries temporais de dados meteorológicos das estações meteorológicas disponíveis no site do Instituto Nacional de Meteorologia (INMET), para parametrização dos algoritmos e; d) Mapeamento das áreas de pastagem, disponibilizado pelo LAPIG para a BHRV.

Assim, inicialmente, foram processadas as imagens OLI/TIRS - Landsat 8, correspondentes à órbita/ponto 222/71; devido à quantidade de nuvens sobre a área de estudo, foram selecionadas as imagens com menor contaminação atmosférica, sendo processadas as imagens obtidas nos dias 18 de outubro de 2014, 06 de janeiro, 23 de fevereiro, 12 de abril, 30 de maio, 15 de junho, 17 de julho, 18 de agosto e 03 de setembro de 2015. Além destas imagens, foram utilizados os dados meteorológicos da estação automática de Goiás - GO (A014), localizada na BHRV, mais especificamente na cidade de Goiás, sob a responsabilidade do INMET.

Para a obtenção da biomassa seca das áreas de pastagem foi estimada a partir da produtividade primária bruta (GPP), que se fundamenta na relação entre a eficiência do uso da luz - LUE e a radiação fotossinteticamente ativa absorvida - APAR, por meio do acoplamento do algoritmo Carnegie Ames Stanford Approach (CASA) no SEBAL. Foram utilizados os seguintes dados meteorológicos: temperatura e umidade relativa do ar, radiação solar global, 
velocidade do vento e pressão atmosférica. No algoritmo SEBAL, utilizou-se a equação do balanço de energia para a estimativa do fluxo de calor latente (LE) como resíduo dos demais componentes (Fluxo de calor no Solo $(\mathrm{G})$, fluxo de calor sensível (H) e o saldo de radiação $(\mathrm{Rn}))$, conforme a equação 02 .

$$
L E=R n-H-G
$$

De posse dos componentes do balanço de energia, foi estimada a fração evaporativa, com base na equação 03 .

$$
F E=\frac{L E}{(R n-G)}
$$

Detalhes da estimativa dos componentes do balanço de radiação e balanço de energia podem ser consultados em Veloso et. al., (2017). A fração evaporativa foi utilizada para a estimativa da GPP, por meio da metodologia proposta por Bastiaanssen e Ali (2003), sendo estimada primeiramente a Radiação Fotossinteticamente Ativa (PAR, em $\mathrm{Wm}^{-2}$ ). Para a estimativa de PAR, foi adotado como fator de aproveitamento da luz solar o valor de 0,58 . $\mathrm{Na}$ literatura especializada, estima-se que a fração de PAR utilizada pela vegetação em seu processo de fotossíntese seja da ordem de aproximadamente 50\%. Estudos realizados por Galvani (2009) indicam razões entre 44\% e 69\%; enquanto que Silva et al. (2013) apontaram que, para a região de Cerrado, o valor de radiação fotossinteticamente ativa representa $58 \%$ da radiação global, aplicável para as estações seca e chuvosa. Estes autores utilizaram os dados do Projeto SONDA para a realização da pesquisa. Por esta razão, adotou-se nesta pesquisa a utilização do mesmo fator de aproveitamento (i.e., 58\%) obtido por Silva et al. (2013). Dessa forma, a PAR foi calculada conforme a equação 04.

$$
P A R=0,58 * \text { Rsolar }
$$

Por sua vez, sabe-se que somente uma parte da radiação fotossinteticamente ativa é absorvida pela vegetação - APAR, encontrada no intervalo do espectro de luz visível entre 0,4 e 0,7 $\mu \mathrm{m}$. Diversos estudos vêm demonstrando uma alta relação entre a FPAR e os índices de vegetação, como o NDVI, pois estes índices são altamente sensíveis à clorofila presente nas plantas, no qual podem apresentar alta correlação entre a radiação incidente e aquela absorvida pela vegetação (SELLERS et al.,1992; POTTER et al., 1993; SELLERS et al., 1997; DEFRIES et al., 1997; FRIEDL, 1997; DEFRIES e Los, 1999; GOETZ et al., 1999). Portanto, para a 
Biomassa seca estimada em áreas de pastagens com dados de sensoriamento remoto: estudo de caso na bacia hidrográfica do rio Vermelho - Goiás

estimativa da FPAR desta pesquisa, foi realizada a correlação entre a FPAR e o NDVI em áreas de pastagens, no intervalo do ano de 2014, utilizando os produtos MOD13Q1H (NDVI) e o MOD15A2 (FPAR). Os coeficientes obtidos nesta relação foram utilizados na estimativa da FPAR com as imagens de NDVI do Landsat 8 OLI/TIRS na BHRV.

Obteve-se um $r=0,61$ o período chuvoso e $\mathrm{p}>$ que 0,0001 . Este resultado está associado à interferência da atmosfera, que no caso das imagens do MOD13Q1 e MOD15A2, mesmo com os filtros de qualidade dos pixels (para evitar nuvens), apresentam muitos ruídos neste período. Para o período de estiagem, onde há pouca interferência da atmosfera, os valores de NDVI e FPAR apresentaram alta correlação, obtendo valores de $r=0,81$ e $p>0,0001$, demonstrando a viabilidade de se estimar a FPAR com as imagens de NDVI do MODIS (250 m). Dessa forma, a FPAR para a pastagem pode ser estimada em função do índice de vegetação por diferença normalizada (NDVI), conforme equação 05, para o período chuvoso, e equação 06 para o período de estiagem.

$$
\begin{array}{r}
\text { FPAR }=0,0564+0,8198 * \text { NDVI } \quad\left(\text { W. m }-{ }^{2}\right) \\
\text { FPAR }=0,004+0,9843 * \text { NDVI } \quad\left(\text { W. } \mathbf{m}-{ }^{2}\right)
\end{array}
$$

Portanto, a estimativa da APAR consiste entre o produto da PAR e FPAR, conforme equação 07.

$$
\mathrm{APAR}=\mathrm{FPAR} * \mathrm{PAR}
$$

Em seguida, foram realizados os cálculos dos escalonares de temperatura T1 e T2, dados pelas equações 08 e 09 (FIELD et al., 1995).

$$
\begin{aligned}
T_{1}=0,8+0,02 T_{o p t}-0,0005 T_{o p t}^{2} \\
T_{2}=\frac{1}{1+\exp \left(0,2 T_{o p t}-10-T_{d i a}\right)}
\end{aligned}
$$

(09)

Onde: Topt é a temperatura do ar média $\left({ }^{\circ} \mathrm{C}\right)$ do mês de máximo NVDI e Tdia é a temperatura do ar média diária $\left({ }^{\circ} \mathrm{C}\right)$. A eficiência do uso da luz - $\varepsilon\left(\mathrm{g} \mathrm{C} \mathrm{MJ}^{-1}\right)$ pode ser quantificada pelo modelo de Field et al., (1995), modificada por Bastiaanssen e Ali (2003), conforme a equação 10.

$$
\varepsilon=\varepsilon^{\prime} \cdot \mathrm{T}_{1} \cdot \mathrm{T}_{2} \cdot \mathrm{FE}
$$


Onde: $\varepsilon$ ' representa eficiência de conversão da radiação fotossinteticamente ativa ou comumente denominada de uso da luz, sendo considerado nesta pesquisa com valor igual a 0,5 g C MJ-1. Estudos realizados por Rosa e Sano (2013) em áreas de pastagens Brachiaria brizantha no cerrado mineiro encontraram valores de eficiência máxima na ordem de $0,46 \mathrm{~g} \mathrm{C}$ $\mathrm{MJ}^{-1}$, Fonseca et al. (2006) encontraram valores e eficiência de utilização da radiação variando de 0,09 a $0,51 \mathrm{~g} \mathrm{C} \mathrm{MJ}^{-1}$ em experimentos de campo para vegetação campestre no Bioma e Campos Sulinos. Machado (2014), em experimento desenvolvido com pastagem Brachiaria Urochloa na unidade da Embrapa Cerrados, em Planaltina - DF, encontrou valores de eficiência máxima de $0,5 \mathrm{~g} \mathrm{C} \mathrm{MJ}^{-1}$. Neste sentido optou-se por utilizar nesta pesquisa o fator de eficiência da luz obtido por Machado (2014). Com a determinação da $\varepsilon$, obteve-se a GPP em g C mª 1 , com base na equação 11 .

$$
\mathrm{GPP}=\mathrm{APAR} \cdot \varepsilon^{\prime} \cdot \mathrm{T}_{1} \cdot \mathrm{T}_{2} \cdot \mathrm{FE}
$$

Para a conversão de GPP em biomassa seca, considerou-se o fator de conversão do carbono em biomassa igual a 2,7. Esta relação entre biomassa seca e carbono foi encontrada em uma pesquisa realizada por Neumann Cosel et. al, (2011), na pastagem de espécie Brachiaria Urochloa, a que predomina no Cerrado. Portanto, a estimativa da biomassa seca com base nas imagens de GPP para a pastagem foi obtida de acordo com a equação 12.

$$
\text { Biomassa seca }=\text { GPP } * 2,7
$$

\section{Análises Estatísticas e Validação}

Para validar os resultados, os dados de biomassa obtidos com a modelagem da BHRV foram comparados com os dados de campo coletados nas fazendas da BHRV (entre outubro de 2014 e outubro de 2015). Foram realizadas análises de correlação de Pearson e regressão linear entre os valores observados e estimados, além de análise dos erros, quantificando o erro absoluto médio (EAM) (Equação 13), a raiz do erro quadrático médio (REQM) (Equação 14) e o índice de concordância de Willmott (d) (Equação 15).

$$
\begin{array}{r}
E A M=\frac{1}{N} \sum_{i=1}^{N} \quad\left[X_{1}-X_{2}\right] \\
R E Q M=\left(\sum_{i=1}^{N} \frac{\left(X_{1}-X_{2}\right)^{2}}{N}\right) \\
d=1-\frac{\sum_{i=1}^{n}\left(X_{1}-X_{2}\right)}{\sum_{i=1}^{n}\left(\left|X_{1}-\underline{X_{2}}+\right| X_{1}-\underline{X_{2}}\right)^{2}}
\end{array}
$$


Biomassa seca estimada em áreas de pastagens com dados de sensoriamento remoto: estudo de caso na bacia hidrográfica do rio Vermelho - Goiás

Onde: $\mathrm{X}_{1}$ é o valor obtido em campo, $\mathrm{X}_{2}$ o valor estimado pelo modelo padrão e $\mathrm{X}$ a média dos valores observados.

\section{RESULTADOS E DISCUSSÃO}

Os dados de campo como a altura do pasto foi uma das variáveis utilizadas para indicar a produtividade das pastagens, uma vez que ao avaliar o crescimento do pasto, no período de coleta, observou-se que a Faz. Jatobá apresentou pastagens quase duas vezes mais altas (em torno de $60 \mathrm{~cm}$ ) do que as demais propriedades (em torno de $30 \mathrm{~cm}$ ), e uma diferença mínima na altura entre os períodos chuvoso e seco (de apenas $4 \mathrm{~cm}$ ). Já na Faz. Ajuricaba apresentou a maior diferença na altura do pasto entre os dois períodos, com pastos duas vezes mais altos no período chuvoso $(52 \mathrm{~cm})$, se comparado ao período seco $(25 \mathrm{~cm})$. A classe de solo predominante nesta propriedade é o Plintossolo que são solos minerais hidromórficos, com séria restrição à percolação de água, encontrados em áreas de alagamento temporário e, portanto, escoamento lento. Ocorre em áreas e relevo plano e suave-ondulado, apresenta horizonte de subsuperficie com manchas avermelhadas distribuídas no perfil, chamadas de plintita (REATTO et al., 2008), estas características favorecem o crescimento da Urochloa no período seco, estas mesmas condições foram observadas por várias pesquisas (FRANÇA E PAIVA, 2015; SANTOS et al., 2018).

As fazendas N. Sra. das Graças e Estância Paraíso apresentam valores de altura muito próximos tanto no período chuvoso (19 e $25 \mathrm{~cm}$, respectivamente) como no seco (29 e $31 \mathrm{~cm}$, respectivamente), o que indica condições ambientais e de manejo semelhantes. A Faz. Dois Córregos apresenta as menores alturas de pastagem, com $6 \mathrm{~cm}$ no período chuvoso e $10 \mathrm{~cm}$ no seco, com solos bastante rasos e pedregosos, o que dificulta o desenvolvimento da Urochloa, associado a um manejo inadequado, o que leva a uma ocorrência de pastagens de baixa altura.

Estes resultados corroboram com aqueles apresentados por Franco e Rosa (2003, 2487), em que as pastagens com menores alturas são aquelas com uma maior degradação do pasto, o que também foi observado nas propriedades desta pesquisa. Naquele estudo, pastagem com $3 \mathrm{~cm}$ em média possuíam alto índice de degradação.

$\mathrm{Na}$ análise da degradação das pastagens a refletância foi uma das variáveis que chamou a atenção, pois quando essa foi medida nas cinco propriedades, nas estações seca e chuvosa, notou-se maior diferença nos comprimentos de onda, em particular no infravermelho próximo, 
variando no azul de 3 a 5\% (seco) e de 3 a $7 \%$ (chuvoso), e no infravermelho próximo de 24 a $35 \%$ (seco) e de 32 a $51 \%$ (chuvoso), respectivamente.

A Região Eletromagnética do visível (REM, intervalos indo do azul ao vermelho) mostra valores de reflectância baixos e próximos para todos os pastos na estação seca, com valores no azul e vermelho semelhantes ao valor do verde, indicativos da baixa atividade fotossintética das pastagens. Já na estação chuvosa, nota-se a prevalência da absorção nos intervalos do azul e vermelho e a menor absorção no verde, indicando a maior atividade fotossintética das pastagens. Na estação seca, a maior reflectância no vermelho indica tanto pastos com muito solo exposto, como pastos secos (baixa atividade fotossintética); no período chuvoso, devido à alta atividade fotossintética das pastagens (alta absorção nos intervalos do vermelho e azul), a maior reflectância no vermelho é indicativo da presença de solo exposto.

Os valores de NDVI para as estações seca e chuvosa foram muito próximos entre todas as propriedades, variando de 0,4 a 0,5 na seca, e até 0,53 a 0,66 na chuva. Na seca há maior diferença nos valores de NDVI entre as pastagens, com os maiores valores para a Faz. Dois Córregos $(0,5)$, seguida da Faz. Jatobá $(0,47)$, da Faz. Ajuricaba $(0,47)$, da Faz. N. Sra. das Graças $(0,4)$ e da Faz. Estância Paraíso $(0,4)$, respectivamente. Na chuva, o maior valor foi para a Faz. Jatobá (0,66), seguido da Faz. Ajuricaba (0,59), Estância Paraíso (0,58), Faz. Dois Córregos $(0,58)$ e N. Sra. das Graças $(0,53)$. Na estação chuvosa há maior variação na resposta entre as propriedades com relação ao NDVI, mas nota-se que a propriedade com pastagem mais produtiva (Faz. Jatobá) tem o maior NDVI.

Estes dados são corroborados pelos trabalhos de Franco e Rosa, 2003; Santos et al., 2018. A porcentagem de verde (com método do pin-point) apresentou o mesmo padrão, com a maior porcentagem de verde para a Faz. Dois Córregos (31\%), seguida da Faz. Ajuricaba (27\%), da Faz. Jatobá (20\%), da Faz. N. Sra. das Graças (15\%) e da Faz. Estância Paraíso $(14 \%)$, respectivamente.

Com base nas estimativas de GPP das imagens do Landsat 8 OLI/TIRS (métodos SEBAL/CASA e MOD17 (modificado com dados do Landsat 8)), foi possível determinar a biomassa seca em áreas de pastagens na BHRV, com uma melhor resolução espacial (30 m). Na Figura 04 estão representados os dados de biomassa seca em kg MS ha ${ }^{-1}$ dia- $^{-1}$ estimados

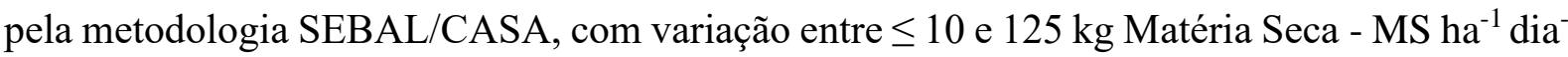
1. Na Figura 05 estão apresentados os dados de biomassa seca estimados pela metodologia MOD17 (L8), com variação entre $\leq 15$ e $110 \mathrm{~kg} \mathrm{MS} \mathrm{ha}^{-1}$ dia $^{-1}$. O método SEBAL/CASA 
Biomassa seca estimada em áreas de pastagens com dados de sensoriamento remoto: estudo de caso na bacia hidrográfica do rio Vermelho - Goiás

apresentou maior amplitude no período analisado, sendo mais sensível à sazonalidade climática. Em ambos os métodos, os maiores valores de biomassa seca foram registrados no período chuvoso, sobretudo nas datas de 06 de janeiro, 23 de fevereiro e 12 de abril de 2015. Para as datas do período chuvoso, a metodologia SEBAL/CASA apresentou valores médios de 73, 86 e $52 \mathrm{~kg} \mathrm{MS} \mathrm{ha}^{-1} \mathrm{dia}^{-1}$ (06 de janeiro, 23 de fevereiro e 12 de abril). No entanto, na data de 18 de outubro de 2014 foram observados valores médios de $18 \mathrm{~kg} \mathrm{MS} \mathrm{ha}^{-1} \mathrm{dia}^{-1}$. Apesar do mês de outubro representar o início do período chuvoso, ainda há deficiência hídrica no solo, provocando baixos valores na produtividade de forragem.

Em contrapartida, no início do período de estiagem (30 de maio), ainda que com redução nas precipitações, o solo ainda apresenta boa disponibilidade hídrica, e consequentemente as pastagens mantêm boa produtividade, sendo registrado neste dia médias de $69 \mathrm{~kg} \mathrm{MS} \mathrm{ha}^{-1} \mathrm{dia}^{-}$ 1. Na data seguinte (15 de junho), registra-se uma leve redução na produção de biomassa seca, com valores médios de $62 \mathrm{~kg}$ MS $\mathrm{ha}^{-1} \mathrm{dia}^{-1}$. A partir do mês de julho, a produtividade de biomassa reduz significativamente, apresentando valores médios de $30 \mathrm{~kg} \mathrm{MS} \mathrm{ha}^{-1} \mathrm{dia}^{-1}$ (17 de julho) e de $21 \mathrm{~kg} \mathrm{MS} \mathrm{ha}^{-1} \mathrm{dia}^{-1}$ (18 de agosto), apresentando reduções em aproximadamente $50 \%$ em relação às datas anteriores. No entanto, na data de 03 de setembro, já é observado um aumento na produtividade de biomassa, devido ao reinício das precipitações, registradas em dias anteriores. Observa-se, assim, que no período de estiagem (sobretudo de julho a setembro) a produção de biomassa é afetada significativamente, devido à baixa umidade solo. Os efeitos deste déficit hídrico mais imediato é o fechamento dos estômatos (provocando redução na condutância estomática), prejudicando a assimilação do carbono pela planta por causa da limitação das trocas gasosas, e por fim reduzindo-se a produtividade (LEMAIRE, 2001).

Comparando-se as duas metodologias (MOD17 e SEBAL/CASA), os valores médios de biomassa seca observados no período chuvoso não demonstraram significativas diferenças; entretanto, no período de estiagem, a metodologia MOD17 (L8) apresentou valores bem acima do método SEBAL/CASA, principalmente nos meses com maior estresse hídrico, como julho e agosto, com valores médios de 54 e $49 \mathrm{~kg} \mathrm{MS} \mathrm{ha}{ }^{-1} \mathrm{dia}^{-1}$, respectivamente. Estes valores foram superiores ao método SEBAL/CASA em aproximadamente $45 \%$ para essas datas. Tal resultado está associado com a estimativa da eficiência do uso da luz em cada método, pois no SEBAL/CASA usa-se a fração evaporativa para a contabilização do fator água na assimilação do carbono pela planta na produção de biomassa. 
Figura 04 - Biomassa seca nas áreas de pastagens na BHRV em Kg ha-1 dia $^{-1}$, pelo

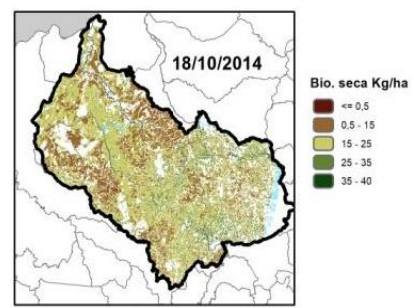
método SEBAL/CASA.
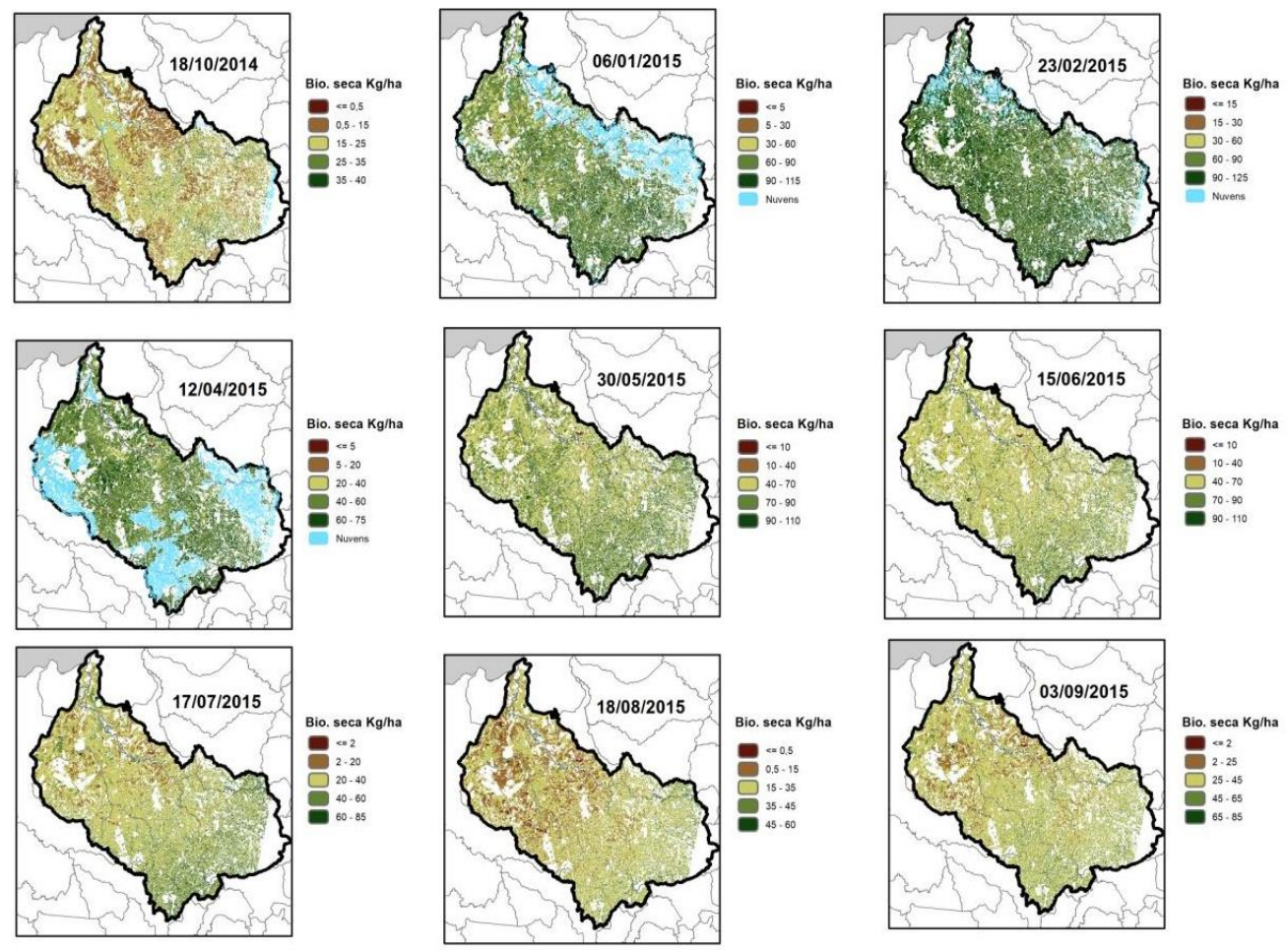

Fonte: autores, 2018.

Figura 05 - Biomassa seca nas áreas de pastagens na BHRV em Kg ha-1 dia $^{-1}$, pelo

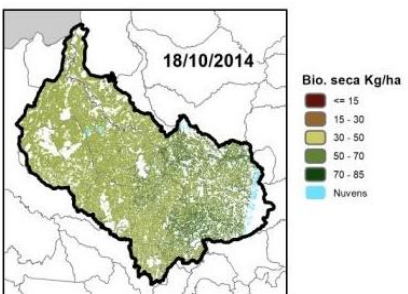
método MOD17 (L8).
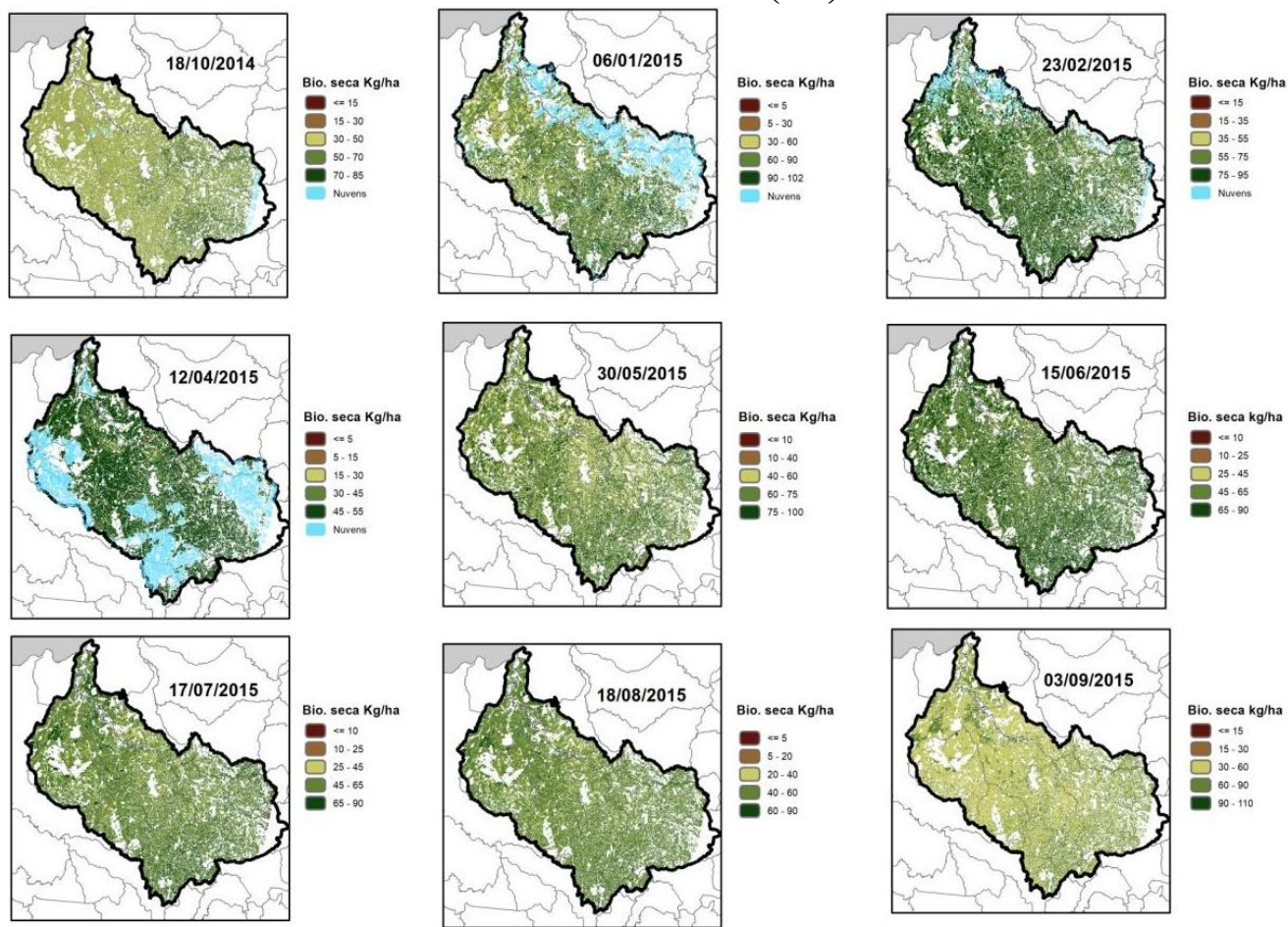

Fonte: autores, 2018. 
Biomassa seca estimada em áreas de pastagens com dados de sensoriamento remoto: estudo de caso na bacia hidrográfica do rio Vermelho - Goiás

No método MOD17 (L8) o valor de eficiência de uso da luz é calculado com os dados da estação meteorológica, relacionados à temperatura mínima do ar e ao déficit de pressão de vapor. Analisando-se ambos os métodos, foi observada uma taxa de acúmulo médio de $45 \mathrm{~kg}$ MS ha ${ }^{-1}$ dia $^{-1}$ para o período de estiagem e de $58 \mathrm{~kg} \mathrm{MS} \mathrm{ha}^{-1} \mathrm{dia}^{-1}$ para o período chuvoso no método SEBAL/CASA. No método MOD17 (L8), o acúmulo médio foi de 57,66 e 57,96 kg MS ha ${ }^{-1}$ dia $^{-1}$ para os períodos de estiagem e chuvoso, respectivamente. Na literatura, foram observados resultados semelhantes, como o experimento realizado por Rodrigues et al. (2011) na fazenda experimental do Instituto de Zootecnia, em Nova Odessa (SP), realizado entre novembro de 2010 e junho de 2011, encontrando-se valores médios de acúmulo da forragem na ordem de 50,5 $\mathrm{kg} \mathrm{MS} \mathrm{ha}^{-1} \mathrm{dia}^{-1}$, com acúmulo total de matéria seca de 10.754,4 $\mathrm{kg} \mathrm{MS} \mathrm{ha}^{-1}$ dia $^{-1}$ em 213 dias. Em um estudo realizado por Ferreira e Barioni (2007) foi estimado um acúmulo de matéria seca em pastagens de Urochloa spp. em Cristalina - GO, na ordem de 39,6; 60,7; 36,4 e 17,8 $\mathrm{kg} \mathrm{MS} \mathrm{ha}^{-1} \mathrm{dia}^{-1}$, respectivamente na primavera, verão, outono e inverno, entre novembro de 2005 e outubro de 2006.

Esses resultados foram menores em relação ao encontrado por Sbrissia (2004), que ao avaliar a taxa de acúmulo de forragem da Brachiaria brizantha $c v$. Marandu, observou-se que a mesma variou de 100 até $115 \mathrm{~kg}$ de MS ha ${ }^{-1} \mathrm{dia}^{-1}$. Essas diferenças de valores de acúmulo de biomassa seca podem estar relacionadas a diversos fatores, como manejo da pastagem, sistema de pastejo, adubação do solo, tipo e fertilidade do solo, e condições climáticas para cada área (temperatura do ar, precipitação média e radiação solar), além do tipo de metodologia empregada na modelagem (RODRIGUES et al., 2011).

Para as cinco propriedades da BHRV, em que foram coletadas a biomassa nas áreas de pastagens durante todo o período de estudo (outubro de 2014 a setembro de 2015), foi calculada a média de produtividade de biomassa seca dessas para cada mês analisado e comparando os valores médios obtidos pelos métodos SEBAL/CASA e MOD17 (L8). Além disso, foi avaliada a estimativa de biomassa seca das áreas de pastagens obtida através do produto MOD17A2H (resolução espacial de 500 metros), com o intuito de avaliar o desempenho deste produto para a BHRV.

A Figura 06 apresenta a variação dos dados estimados pelas imagens de satélite e pelos dados coletados em campo, sendo que os valores obtidos pelo produto MOD17A2H apresentaram-se superestimados, sobretudo no período chuvoso. Este resultado pode estar associado aos dados de entrada no algoritmo do MOD17A2, no qual indica que o valor de LUE 
pode ser alto para as áreas de pastagens no Cerrado, bem como os dados meteorológicos do GMAO podem ocasionar possíveis erros (baixa resolução espacial). No entanto, para o período de estiagem, os valores de biomassa seca apresentam significativa redução, apresentando seu valor mínimo no mês de agosto.

Figura 06 - Dados de biomassa seca estimados com imagens de satélite e em campo.

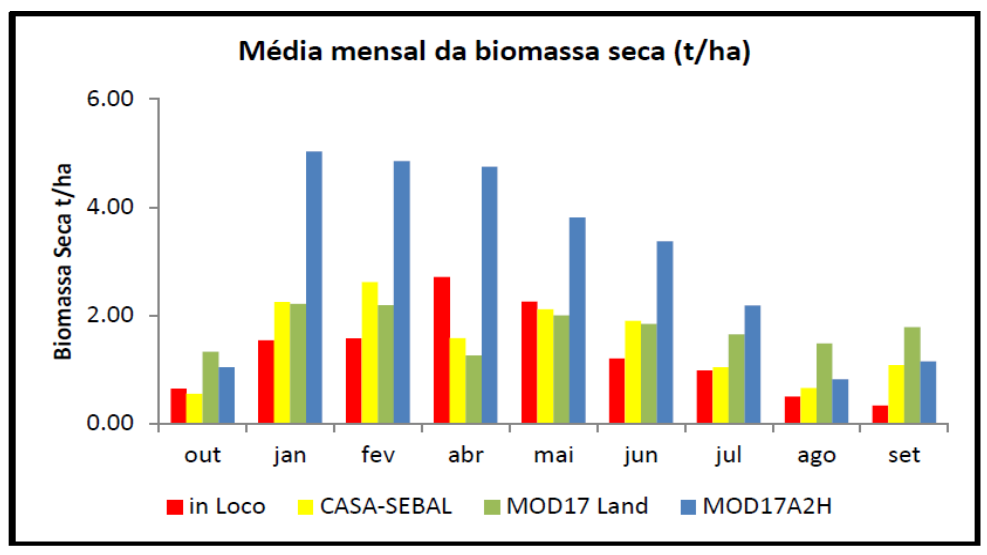

Fonte: dos autores, 2018.

Observa-se que, mesmo no período de estiagem, os valores obtidos pelo produto MOD17A2H se mantiveram superiores aos observados em campo, apresentando, contudo, menor amplitude entre os dados observados (in loco) e os estimados por imagens de satélite. Os valores estimados com as imagens do Landsat 8 (Métodos SEBAL/CASA e MOD17 (L8)) ficaram mais próximos dos obtidos em campo, apresentando uma discrepância no mês de abril (12 de abril de 2015), podendo este resultado ter sido influenciado pela alta nebulosidade deste dia, interferindo na estimativa da biomassa. Este fato demonstra que as condições atmosféricas de alta nebulosidade é um fator limitante na estimativa desses parâmetros com imagens de satélite.

Para a análise do desempenho dos métodos aplicados nesta pesquisa (SEBAL/CASA e MOD17 (L8)) e do produto MOD17A2H, foram estimados os parâmetros estatísticos do índice de correlação de Pearson, estimativa do erro absoluto médio, da raiz do erro quadrático médio e do índice de concordância de Willmott, levando-se como referência os dados obtidos em campo.

Na Tabela 01 observa-se que os parâmetros estatísticos de correlação de Pearson e concordância de Willmott apresentaram resultados mais satisfatórios para o produto MOD17A2H do que para o método MOD17 (L8). No entanto, os valores dos erros observados no método MOD17 (L8) foram inferiores àqueles observados no produto MOD17A2H - este 
Biomassa seca estimada em áreas de pastagens com dados de sensoriamento remoto: estudo de caso na bacia hidrográfica do rio Vermelho - Goiás

último apresentou erros significativos em relação aos observados em campo. Willmott (1981) ressalta que nem sempre uma elevada correlação indica boa precisão do modelo em estimar determinada variável de interesse. Dessa forma, o método MOD17 (L8) pode ser considerado mais eficiente que o produto MOD17A2H em estimar a biomassa da pastagem na BHRV, por ter apresentado erros significativamente menores.

Tabela 01 - Índices de correlação de Pearson, erro absoluto médio (EAM), raiz do erro quadrático médio (REQM) e índice de concordância de Willmott (d) para áreas de pastagem da BHRV.

\begin{tabular}{|c|c|c|c|c|}
\hline Métodos & $\begin{array}{c}\text { Correlação de } \\
\text { Pearson }\end{array}$ & $\begin{array}{c}\text { EMA } \\
\text { t/ha }\end{array}$ & $\begin{array}{c}\text { REQM } \\
\text { t/ha }\end{array}$ & $\mathrm{d}$ \\
\hline SEBAL/CASA & 0,633 & 0,228 & 0,665 & 0,754 \\
\hline $\begin{array}{c}\text { MOD17 } \\
\text { Landsat 8 }\end{array}$ & 0,119 & 0,444 & 0,906 & 0,376 \\
\hline MOD17A2H & 0,833 & 1,858 & 2,133 & 0,483 \\
\hline
\end{tabular}

Fonte: autores, 2018.

O método SEBAL/CASA demonstrou ser o mais eficiente na estimativa da biomassa seca na BHRV, apresentando os menores erros e bons índices de correlação e concordância. Outra maneira de avaliar o desempenho dos métodos na estimativa da biomassa seca é relacioná-la com a capacidade de suporte destas áreas de pastagem, ou seja, a capacidade de produtividade animal (ganho de peso), dependente das pastagens.

Figura 07 - Unidade Animal por hectare para as pastagens na BHRV, avaliadas no período dessa pesquisa pelos métodos SEBAL/CASA e MOD17 (L8).

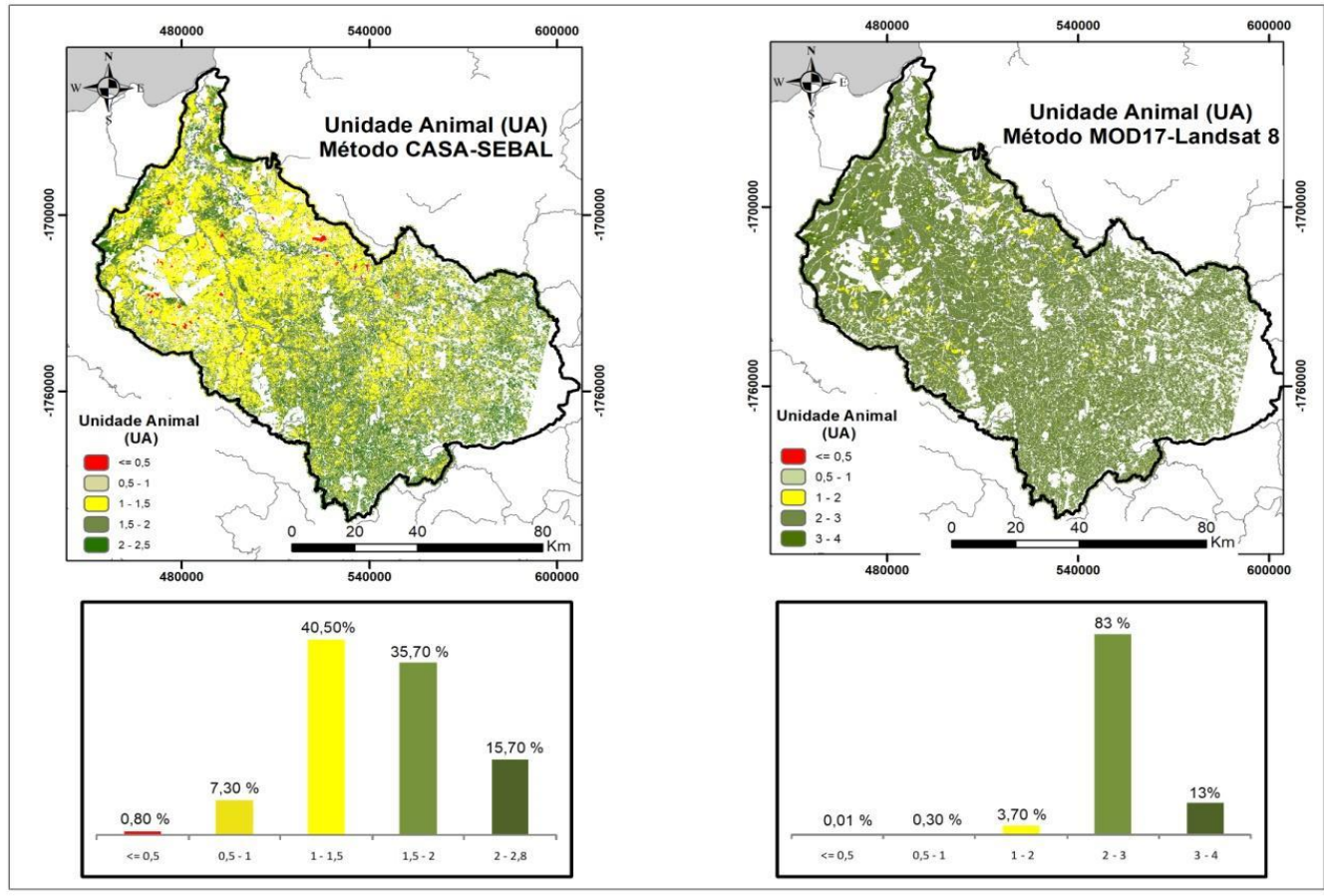

Fonte: autores, 2018. 
Assim, a capacidade de suporte obtida a partir da relação entre a biomassa seca estimada e a demanda de pastagem para uma unidade $(1 \mathrm{UA}=450 \mathrm{Kg})$, a qual corresponde a duas vezes ao seu consumo. Arantes et al. (2018) discutem que a ingestão diária de matéria seca é, em média, de 2,5\% do peso vivo animal (450 Kg), isto é, 11,25 Kg de matéria seca, e que a demanda de forragem precisa ser duas vezes maior do que o consumo, uma vez que parte da forragem disponível não é utilizada (e sim pisoteada). Deste modo, é necessário dividir o consumo de matéria seca pela eficiência da colheita, obtendo-se uma demanda diária de 22,5 kg de matéria seca para cada animal com peso médio de $450 \mathrm{Kg}$ (ARANTES et al., 2018).

Para tanto, foi calculada a capacidade de suporte na BHRV (Figura 07) com as metodologias SEBAL/CASA e MOD17 (L8), sendo que na primeira foi observada variação de 0,5 a 3 unidade animal (UA) por hectare, com predominância entre as classes de 1 e 1,5 UA/ha (40,22\% das áreas de pastagens) e entre as classes de 1,5 e 2 UA/ha (35,43\% das áreas de pastagens) para o período analisado, apresentando valor médio de 1,5 UA/ha.

Na metodologia MOD17 (L8) foi observado valores mais elevados, variando de 0,5 a 4,5 UA/ha, com valores predominantes na classe de 1,5 a 2,5 UA/ha $(53,2 \%$ das áreas de pastagens) e entre 2,5 a 3,5 UA (43,6\% das áreas de pastagens), apresentando valor médio de 2,5 UA/ha.

\section{CONSIDERAÇÕES FINAIS}

Os resultados desta pesquisa evidenciam o potencial do uso de imagens de sensoriamento remoto para a estimativa de dados biofísicos em áreas de pastagem, tais como a biomassa seca e capacidade de suporte bovino, por Unidade Animal/Hectare. A análise destes dados com a utilização de imagens de satélite possibilitou um acompanhamento contínuo desses parâmetros nas áreas de pastagens do Cerrado goiano, especialmente na Bacia Hidrográfica do Rio Vermelho, diferentemente das análises que utilizam estações meteorológicas e dados de biomassa obtidos em campo, normalmente restritos à análises pontuais.

O método que apresentou resultados mais satisfatórios na Bacia Hidrográfica do Rio Vermelho (BHRV) foi o SEBAL/CASA, com boa correlação com a biomassa coletada em campo. Igualmente, este método apresentou o menor erro absoluto médio (EAM), a menor raiz do erro quadrático médio (REQM) e um bom índice de concordância de Willmott. A biomassa seca estimada com o produto do MOD17A2H para as áreas de pastagens da BHRV apresentou boa correlação, ainda que observados erros elevados. Dessa forma, os dados estimados de 
Biomassa seca estimada em áreas de pastagens com dados de sensoriamento remoto: estudo de caso na bacia hidrográfica do rio Vermelho - Goiás

biomassa seca com este produto na BHVR foram superestimados, principalmente nos meses do período chuvoso, podendo este resultado estar associado aos valores de LUE adotados nesta metodologia (comum a todas as savanas do globo terrestre), bem como erros relacionados aos parâmetros climáticos (baixa resolução espacial) no mapa de referência do MOD12Q1 (uso do solo gerado com dados MODIS).

Constatou-se, assim, a importância da calibração desses modelos para as estimativas mais coerentes da biomassa seca, sendo que a utilização da eficiência de uso da luz - LUE específica para a Urochloa, a utilização de um mapeamento detalhado das áreas de pastagens para a BHRV, bem como a utilização de dados climáticos locais reforçam a tese de melhor precisão nessas estimativas.

Por fim, recomenda-se mais experimentos que investiguem a eficiência máxima da Luz para diversos tipos de espécies de gramíneas, tais como Brachiaria, Panicum, Andropogon, etc., bem como estudos mais detalhados da interação da radiação solar para a produção da biomassa, principalmente parâmetros como o FPAR.

\section{REFERÊNCIAS}

ARANTES, A. E.; COUTO, V. R. D. M. Livestock intensification potential in Brazil based on agricultural census and satellite data analysis. Pesquisa Agropecuária Brasileira, v. 53, n. 9, p. 1053-1060, 2018.

BASTIAANSSEN, W. G.; ALI, S. A new crop yield forecasting model based on satellite measurements applied across the Indus Basin, Pakistan. Agriculture, Ecosystems \&amp; Environment, v. 94, n. 3, p. 321-340, 2003.

DEFRIES, R. S.; LOS, S.O. Implications of land-cover misclassification for parameter estimates in global land-surface models: an example from the Simple Biosphere Model (SiB2). Photogrammetric Engineering \& Remote Sensing, v. 65, n. 9, p. 1083-1088, 1999.

FERREIRA, A. C.; BARIONI, L. G. Monitoramento da massa de forragem e altura para ajustes de taxa de lotação em fazenda agropecuária na região do Cerrado. Planaltina, DF: Embrapa Cerrados: (Boletim de Pesquisa e Desenvolvimento, 191) 24 p. 2007.

FIELD, C. B.; RANDERSON, J. T.; MALMSTRÖM, C. M. Global net primary production: Combining ecology and remote sensing. Remote Sensing of Environment, v. 51, n. 1, p. 74 88, 1995.

FONSECA, E. L. da.; SILVEIRA, V. C. P.; SALOMONI, E. Eficiência de conversão da radiação fotossinteticamente ativa incidente em biomassa aérea da vegetação campestre natural no bioma Campos Sulinos do Brasil. Ciência Rural, Santa Maria, v. 36, n. 2, p. 656$659,2006$. 
FRANCO. J. B. S., ROSA, R. Metodologia de coleta de dados radiométricos em pastagens do gênero Brachiaria com diferentes estágios de degradação, in: Anais do XI Simpósio Brasileiro de Sensoriamento Remoto. p; 2483-2491, 2003.

FRANÇA, A., M., da S., Estimativa e modelagem de estoques de carbono em solos sob áreas de campo limpo úmido do distrito federal, Sociedade e Natureza, Uberlândia, 27 (1): 171184 , jan/abr/2015.

FRIEDL, M. A. Examining the effects of sensor resolution and sub-pixel heterogeneity on spectral vegetation index: implications for biophysical modeling. In: Quattrochi, DA.; GOODCHILD, M.F. eds. Scale in Remote Sensingand GIS. Boca Raton: Lewis Publishers, Cap. 6, p.113-136, 1997.

GALVANI, E. Avaliação da Radiação Solar Fotossinteticamente Ativa (PAR) em São Paulo, SP. GEOUSP Espaço E Tempo (Online), 13(1), 155-164, 2009.

GOETZ, S. J; PRÍNCIPE. S. D.; GOWARD, S. N.; THAWLEY, J. S. Satellite remote sensing of primary production: an improved production efficiency modeling approach. Ecological Modelling, v. 122, n. 3, p. 239-255, 1999.

GRISI, B. M. Glossário de Ecologia e Ciências Ambientais. Editora da Universidade Federal da Paraíba. João Pessoa - PB, 2000.

GUSSON, E. Avaliação de método para a quantificação de biomassa e carbono em florestas nativas e restauradas de mata atlântica. Tese (Doutorado em Recursos Florestais) - Universidade de São Paula, São Paulo. 112p, 2014.

LEMAIRE, G. Ecophysiology of grasslands Aspects of forage plant populations in grazeds wards. In: Proc. XIX International Grassland Congress. Brazilian Societyof Animal Husbandry, Sociedade Brasileira de Zootecnia (eds.). São Pedro, São Paulo. Brasil. pp:29-37, 2001.

MACHADO, P. M. Séries Temporais do MODIS em Pastagens Cultivadas do Cerrado: Comparação com dados Espectorradiométricos de Campo. Dissertação do Programa de PósGraduação Geociências Aplicadas. Universidade Federal de Brasília - UNB, Brasília, 2014.

MCKANE, R. B.; RASTETTER, E. B.; MELILLO, J.; SHAVER, G. R.; HOPKINSON, C.; FERNANDES, D.; SKOLE, D.; CHOMENTOWSKI, W. Effects of global change on carbon storage in tropical forests of South America. Global Biogeochemical Cycles, v. 9, n. 3, p. 329-350, 1995.

MONTEITH, J. L. Solar radiation and productivity in tropical ecosystems. Journal of Applied Ecology, v.9, p.747-766, 1972.

NEUMANN-COSEL, L.; ZIMMERMANN, B.; HALL, J. S.; BREUGEL, M. V.;

ELSENBEER, H. Soil carbon dynamics under young tropical secondary forests on former 
Biomassa seca estimada em áreas de pastagens com dados de sensoriamento remoto: estudo de caso na bacia hidrográfica do rio Vermelho - Goiás

pastures A case study from Panama. Forest Ecology and Management, v. 261, n. 10, p. 1625-1633, 2011.

PAIVA, C. M.; FERNANDES, R. F. Estudo da Produtividade Primária do Bioma Mata Atlântica via Sensoriamento Remoto. Anuário do Instituto de Geociência - UFRJ. v. 38-2. p. 15-14, 2015.

PARENTE, L.; MESQUITA, V.; MIZIARA, F.; BAUMANN, L.; FERREIRA, L. Assessing the pasturelands and livestock dynamics in Brazil, from 1985 to 2017: A novel approach based on high spatial resolution imagery and Google Earth Engine cloud computing. Remote Sensing of Environment, v. 232, p. 111301, 2019.

POTTER, C. S.; DAVIDSON, E. A.; KLOOSTER, S. A.; NEPSTAD, D. C. Regional application of an ecosystem production model for studies of biogeochemistry in Brazilian Amazonia. Global Change Biology, v. 4, n. 3, p. 315-333, 1998.

POTTER, C. S.; RANDERSON, J. T.; FIELD, C. B.; MATSON, P. A.; VITOUSEK, P. M.; MOONEY, H. A.; KLOOSTER, S. A. Terrestrial ecosystem production: A process model based on global satellite and surface data. Global Biogeochemical Cycles, v. 7, n. 4, p. 811$841,1993$.

RASTETTER, E. B.; RYAN, M. G.; SHAVER, G. R.; MELILLO, J. M.; NADELHOFFER, K. J.; HOBBIE, J. E.; ABER, J. D. A general biogeochemical model describing the responses of the $\mathrm{C}$ and $\mathrm{N}$ cycles in terrestrial ecosystems to changes in $\mathrm{CO} 2$, climate, and $\mathrm{N}$ deposition. Tree Physiology, v. 9, n. 1-2, p. 101-126, 1991.

REATTO.A., CORREIA, J. R., SPERA, S. T., MARTINS, E. S., Solos do Bioma Cerrado: Aspectos Pedológicos, In: Cerrado: Ecologia e Flora, Orgs. SANO. S. M.. ALMEIDA, S. P. RIBEIRO, J. F., EMBRAPA CERRADOS, BRASÍLIA-DF, 2008;

RODRIGUES, C. A. G.; GREGO, C. R.; GIMENES, F. M. DE A.; ALMEIDA, C. G. F. DE; OLIVEIRA, A. Taxa de acúmulo de matéria seca e biomassa aérea de uma pastagem de capim braquiária 2011. Campinas: Embrapa Monitoramento Por Satélite, 30p, 2011.

RUNNING, S. W.; COUGHLAN, J. C. A general model of forest ecosystem processes for regional applications I. Hydrologic balance, canopy gas exchange and primary production processes. Ecological Modelling, v. 42, n. 2, p. 125-154, 1988.

SANTOS, P. S. Caracterização e mapeamento biofísico ambiental da bacia hidrográfica do rio Vermelho a partir de dados remotamente sensoriados. - 2014. 157 fls. Tese (Doutorado) Universidade Federal de Goiás, Instituto de Estudos Socioambientais, 2014.

SANTOS, P., S., FERREIRA, L. G., LENZI, Í., L., C., Caracterização biofísica das pastagens na bacia hidrográfica do Rio Vermelho (GO), bioma cerrado, Brasil, Boletim Geografico, Maringá, v. 36, n. 3, p. 53-73, 2018;

SBRISSIA, A.F.; DA SILVA, S.C. Compensação tamanho/densidade populacional de per filhos em pastos de capim-marandu. Revista Brasileira de Zootecnia, v.37, p.35-47, 2008; 
SELLERS, P. J. Modeling the Exchanges of Energy, Water, and Carbon Between Continents and the Atmosphere. Science, v. 275, n. 5299, p. 502-509, 1997.

SELlERS, P.; BERRY, A.; COLLATZ, G.; CAMPO, C. B.; HALL, F. G. Canopy reflectance, photosynthesis, and transpiration. III. A reanalysis using improved leaf models and a new canopy integration scheme. Remote Sensing of Environment, v. 42, n. 3, p. 187216, 1992.

SILVA, F. B. Modelagem da Produtividade Primária Bruta na Amazônia. Tese de Doutorado do Curso de Pós-Graduação em Sensoriamento Remoto. Instituto Nacional de Pesquisas Espaciais - INPE, São José dos Campos, 2013.

VELOSO, G. A.; FERREIRA, M. E.; SILVA, B. B. Determinação da evapotranspiração real diária em áreas irrigadas do projeto Jaíba (Minas Gerais, Brasil), mediante imagens Landsat 5 - TM. Revista Cerrados (Unimontes), v. 15, p. 53-76, 2017.

VELOSO, G. A.; FERREIRA, M. E.; FERREIRA, L. G.; SILVA, B. B. Modelling gross primary productivity in tropical savanna pasturelands for livestock intensification in Brazil. Remote Sensing Applications: Society and Environment, v. 17, p. 100288, 2020.

VIEIRA, P. A. Dinâmica de ocupação, vulnerabilidades e cenários para bacia hidrográfica do Rio Vermelho, Goiás. Tese (Doutorado) - Universidade Federal de Goiás, Instituto de Ciências Biológicas. p. 93, 2013.

VIEIRA, P. A.; FERREIRA, M. E., FERREIRA, L. G. Modelagem Dinâmica da Paisagem Aplicada na Análise de Uso do Solo na Bacia Hidrográfica do Rio Vermelho, Goiás, Brasil.

Revista Brasileira de Cartografia (Impresso), v. 1, p. 6, 2015.

WILLMOTT, C. J. On the validation of models. Physical Geography, Delaware, v. 2, p. 184194, 1981.

Recebido em Setembro de 2020

Aprovado em Novembro de 2020

Publicado em Fevereiro de 2021 